\title{
Q Ley y orden. Buenos Aires, hacia fines de $1820^{1}$
}

Fabián Herrero²

"Que la ley sea siempre más poderosa que los hombres" ${ }^{\prime 3}$.

E el centro de toda la empresa política de los directoriales de Bue-nos Aires sobresale un discurso proclive a la ley y al orden. Q uizá sea ésta una de las razones que explica en buena medida por qué dentro de ese esquema argumental, los "otros", los que se manifiestan en su contra, fueron juzgados como los brutales y verdaderos anarquistas de la revolución, como aquellos obstinados e intratables sujetos que sólo se empeñan con su intervención pública en producir los focos de los desordenes y de las rebeliones, con el fin de de atentar y quebrar el espacio legal. Por supuesto, ese conjunto de hombres es heterogéneo y remite a muy diferentes escenarios y tiempos. Entre ellos figuran los federales artiguistas y los confederacionistas porteños, pero también los españoles (aquellos viejos mandones) y los "odiados" portugueses que no dejan de amenazar e incursionar bélicamente en las largas orillas del Río de la Plata. En estas páginas quiero examinar uno de los puntos más altos de ese discurso, el que se reproduce y se difunde en Buenos Aires justamente sobre los escombros de los sucesos de octubre de 1820.

El fracaso de la revolución federal consolida en el poder al flamante gobernador directorial M artín Rodríguez. En dos estudios anteriores (Herrero 2003 y 2007) intenté definir el acontecimiento determinando, al mismo tiempo, el perfil de los protagonistas y sus formas de organización. En esta línea también analicé cuáles fueron las causas

1 Esta investigación forma parte de un volumen inédi to, Fabián Herrero, Movimiento de Pueblo. La política en Buenos Aires luego de 1810, 2006. Agradezco las útiles y amables observaciones formuladas por los dos comentaristas de la revista.

2 Conicet-Instituto Ravignani (UBA).

3 "Prospecto", Legión del Orden o Voz del Pueblo, sinfecha. 
que los llevaron a la acción armada y cuáles eran, además, las creencias que los guiaban, particularmente la imagen que dibujaron de su adversario y su propuesta política provincial.

En el presente trabajo, mi principal centro de interés está dirigido a entender al gunas cuestiones ocurridas en los días posteriores al golpe de estado. En una primera parte, examino cuáles son las actitudes que el grupo vencedor adoptó con relación al contingente político vencido. Exploro, además, las líneas discursivas proclives al orden y a la reconciliación que pueden detectarse en la prensa porteña.

En una segunda sección, me interesa observar cómo perciben la Ilamada "revolución federal". Esto es, qué relación tienen por ejemplo las irrupciones políticas con el marco legal porteño. Q uisiera señalar, en este sentido, cuáles son los problemas que esa emergencia política produce. Antes de comenzar, conviene señalar algunas cuestiones relacionadas con el cuadro político posrevolucionario.

\section{El marco político inicial después del golpe militar de octubre}

Luego de haber sofocado el conflicto federal, Martín Rodríguez camina, al parecer indefectiblemente, hacia la construcción de una nueva etapa de poder directorial. Inmediatamente decide imponer algunas medidas extraídas de su propio arsenal político. Esto es, aquellas medidas que con otra suerte trata de implementar en los meses previos Ildefonso Ramos M ejía. ¿Cuáles? Evoquemos algunas de ellas.

La primera remite a la idea de reforzar el poder del ejecutivo provincial. Como es habitual durante los días de crisis y desorden, la Junta de Representantes otorga al primer mandatario amplias facultades especiales 4 . Solo algunos días más tarde, exactamente, el 16 de octubre, ese mismo poder crea, a instancias de aquél, un Consejo Consultivo

4 El gobernador tuvo dudas sobreed al cance de las amplias facultades quesele concedían y después deescuchar la opinión del Secretario de Gobiemo, Presidentedela Cámara deA pelaciones y Asesor general, resolvió consultar a la J unta si “ellas eran extensivas a rebelar al gobernador de los trámites que prescriben las leyes para la formación de causas (...) y discutida esta gravemateria con presencia de lo que antes se resolvió en acuerdo de ayer 6 y circunstancia en que se halla $\mathrm{d}$ país, seacordó por unanimidad de votos se le contestase. . .diciendo que podrá proceder al juicio de los reos, e imposición de las penas por los medios que lo cercioren del delito y delincuentes sin detenerse en la lentitud y trabas de las fórmulas ordinarias por exigirlo así la suprema ley de la salud pública de esta benemérita Ciudad y Provincia". Acuerdos de la Honorable J unta de Representantes dela provincia deBuenosAires (1820-1821), Publicaciones del Archivo Histórico de la Provincia de BuenosAires, La Plata, 1932, vol. 1. Véase, sesión, 7 de octubre de 1820. 
compuesto de tres personas "que reúnan a sus talentos la honradez y juiciocidad que demanda tal cargo" ${ }^{\prime 5}$. Es de notar que éste flamante cuerpo político no tiene ningún poder de control. Por este motivo, el gobernador se reserva para él: "la libertad de seguir o no el dictamen de dicho Consejo en los asuntos que quiera consultarlo durante el tiempo de las amplias facultades que se le tienen concedidas" ${ }^{\prime 6}$. Este tipo de espacio institucional fue adoptado durante el decenio revolucionario, aunque con diferentes atribuciones, y tiene como principal finalidad ofrecer una mayor dosis de legitimidad al nuevo gobierno.

El conflicto abierto con la provincia de Santa Fe constituye el tema de la tercera medida adoptada por el gobernador. La cuestión finalmente se resuelve en los términos que, desde hace un tiempo atrás, sostienen tanto Rodríguez como Rosas, es decir, a partir del marco que ofrece el método de la negociación y el diálogo ${ }^{7}$. Este acontecimiento es bastante conocido. Juan Baustista Bustos, gobernador de Córdoba, comienza las gestiones de mediación entre ambos gobiernos. El tratado se realiza en la estancia de Benegas, en el límite de las dos provincias, el día 24 de noviembre de 1820. Este documento compromete a López a abandonar la provincia y a ambos gobiernos, a enviar oportunamente representantes a un Congreso que debe reunirse en la ciudad mediterránea. Por una cláusula secreta, se establece la entrega al gobierno de Santa Fe de 25.000 cabezas de ganado. Este último requisito es cumplido por Rosas, quien con ayuda de otros hacendados concreta dicha promesa en el término de tres años ${ }^{8}$.

La tercera medida está asociada a la relación del cuerpo capitular con su brazo armado. Como es sabido, las brigadas cívicas (como veremos de inmediato), dejaron de pertenecer al área de influencia del

5 Acuerdos de la Honorable J unta... ob. cit, sesión 16 de octubre 1820.

6 Acuerdos dela Honorable J unta... ob. cit, sesión 16 de octubre 1820.

7 Distintos testimonios muestran esa intención de las autoridades de Buenos Aires. LaJ unta de Representantes acepta la comisión medi adora de la provincia de Córdoba "a fin de conseguir la paz entre esta provincia y la ciudad y gobierno de Santa Fe, que facilitela organización de un Congreso general que constituya el país y le dé carácter de Nación..." Acuerdos de la HonorableJ unta. . . ob. cit, sesión 23 de octubre de 1820. A probó, también, una nota compuesta de 16 artícul os para arreglar sus diferencias con la ciudad y el gobiemo de Santa Fe. Acuerdos de la Honorable J unta... ob. cit, sesión 24 de octubre de 1820. Pueden consul tarse además "Provincias interiores. Córdoba", La Gaceta, 1 de noviembre de 1820 y "Oficio del excelentísimo señor gobernador y capitán general en campaña al señor gobernador sustituto", La Gaceta, 8 de noviembre de 1820.

8 Véase Sal días 1988: 88-90, Busani che 1984: 422-424, Hal perin Donghi 1972: 349. 
Cabildo de Buenos Aires. A partir de octubre, su nueva dependencia es la del ámbito del poder ejecutivo provincial ${ }^{9}$. U no de los hermanos Anchorena, como diputado de orientación centralista en la Junta de Representantes, había presentado unos antes un proyecto similar. De esta forma la cuestión retorna otra vez a escena, pero ahora es un poder directorial consolidado el que puede darle forma legal a la reforma. La cuarta se relaciona con la revolución de octubre. Se inicia un juicio a los sospechosos de haber participado en ella. De este último punto me ocupo en las páginas que siguen.

Como ya habrá advertido el lector, la maquinaria política directorial comienza así a ponerse en marcha, en la medida que logra concretar, una a una, algunas de sus iniciativas previamente frustradas ${ }^{10}$.

Ahora bien, ¿hay algún tipo de resistencia dentro de los partidarios del grupo vencedor? Sí, esa resistencia efectivamente existe. Es promovida justamente por ese inquieto cura y periodista, de clara orientación antifederal y antimontonero, Ilamado Francisco Castañeda ${ }^{11}$ ¿Qué cuestiones de la política oficial rechaza? De manera categórica cuestiona, en primer lugar, esa señal ada política de reconciliación sostenida y difundida por los principales líderes que vencieron en octubre. El conocido manifiesto publicado por Juan Manuel de Rosas, en donde claramente hace un Ilamado a la unidad de los porteños, ofrece la ocasión y la oportunidad al padre franciscano para señalar su decepción por el curso que están tomando las cosas públicas. A sus ojos

“...lo intolerable en el manifiesto es aquello de, 'me despido compatriotas: el quinto regimiento del Sud de todos es amigo, de todos es hermano, primero, segundo y tercero cívicos, ciudadanos todos, y cada uno recibid los votos que os hago presentes a nombre de la división que mando...' ¡Por Dios, por Dios! ¡O h joven comandante del 5to regimiento!, no seas tan encantador, tan déspota y tan tirano! bastantes lágrimas ha derramado el pue-

9 El Cabil do, por su parte, había manifestado la absoluta fal ta defondos para sostener los gastos de los cuerpos cívicos. Oficio de la Junta al Gobernador, en acta del cabildo, Acuerdo del Extinguido Cabil do de Buenos Aires, año 1820. Véesesesión, 20 deoctubre de 1820 y publicado en La Gaceta, 25 de octubre 1820. Sobre esta cuestión véase además, Acuerdos dela Honorable J unta... ob. cit, sesiones, 6,12 y 19 de octubre de 1820.

10 Véase al respecto Herrero 1999:122-125.

11 Una primera aproximación sobre este tema en Herrero 2002. 
blo y la provincia en que naciste: joven cruel! ¡Basta ya de lutos, basta ya de llantos!..."12.

La otra impugnación se asocia de algún modo con la primera, en cuanto Castañeda no desea ningún tipo de diálogo con nadie que, hasta ayer (o antes de ayer), hubiera estado del otro lado de la trinchera política y militar. Así, también niega cualquier trato de orden pacífico con los federales del litoral, impulsando y promoviendo, en cambio, una política enteramente guerrera contra esos caudillos que invadieron Buenos Aires por el simple motivo de querer "Ias vaquitas de Buenos Aires" y de estar permanentemente "enamorados de las cosas ajenas" ${ }^{13}$.

Sobre esta base, también cuestiona a la prensa que apoya al gobierno provincial. Desde las columnas de El Despertador le contesta, justamente, a La Legión del Orden: "U.D. preguntó en su prospecto, ¿podrá asomar otra vez el monstruo de la anarquía? Y yo debo responderla que sí y que asomará sin duda..."14. Con esta convicción, sostiene que los focos de desordenes y de caos continuarán formando parte del paisaje nacional sino se elimina completamente de él a "los federales de adentro y de afuera"; es decir, a los partidarios de este signo tanto de origen porteño como provinciano ${ }^{15}$.

Castañeda, por consiguiente, decide seguir participando del combate de orden simbólico librado en el dominio público provincial. Ese áspero enfrentamiento señala, con entera claridad por otra parte, que hay resistencias dentro del abanico de propuestas ofrecidas desde el bando que acaba de derrotar a los federalistas porteños. No hay,

12 "Prosigue la relación de lo acaecido el día 5 de octubre contra los montoneros de adentro", EI Despertador Teofilantrópico Mistico-Politico, 14 deoctubre de 1820.

13 "Carta de "Doña para nosotras nadie mejor que nosotras mismas", El Despertador Teofilántropico Místico-Político, 16 de noviembre de 1820.

14 “Mi Sra. Doña Legión del Orden”, Despertador Teofilantrópico, 27 de noviembre de 1820.

15 Es de destacar, asimismo, que los diarios de Castañeda no tienen una misma estrategia sobre estos temas. El Desengañador, por ejemplo, prefiere moderar su tono antifederal, distanciándose, de esa manera, de la postura intransigente y hostil que ha asumido El Despertador. En un tono racista se sostiene que “...El Gauchi-Político se ha retirado a cuarteles de invierno, creyendo queya Dios nos ha librado de fedefragos. El suplementista no piensa más queen sus cosas, creyendo que en estemomento ya no hay enamorados de las cosas ajenas. El Paral ipómenon sólo aborrece a los judios, y no habiendo judios, ya le parece que en Buenos Aires, no hay un solo judio, siendo asi que hay tantos y los peor es que ni por el pensamiento les pasa el ahorcarse de al gún árbol, porque no estan desesperados de vol ver a enfederarnos..." Carta de "Doña para nosotras nadie mejor que nosotras mismas", El Despertador Teofilántropico Místico-Político, 16 de noviembre de 1820. 
en efecto, un discurso monolítico proclive a la ley y al orden. Sin embargo, dichas líneas discursivas tienen una vida breve y quedan rápidamente aisladas, ya que en poco tiempo (y por otras razones) su máximo promotor es expulsado de la provincia.

Q uisiera detenerme ahora en una de las propuestas. La que tiene que ver con la actitud tomada frente a los responsables de esa "revolución". En este sentido, la línea de acción desplegada por el sector directorial puede cifrarse en lo siguiente: exclusión de los federales rebeldes y reconciliación con aquellos que estén dispuestos a reintegrarse al nuevo orden.

\section{Pensar al "otro"}

\section{Exclusión}

Luego que los porteños atravesaran la sangre y el polvo que dejan (casi siempre) los intentos revolucionarios, no puede resultar extraño que se produzca, fatalmente, la exclusión de todos aquéllos que no están dispuestos a dar precisas y claras señales de respecto y conformidad de las nuevas condiciones políticas. En línea con este razonamiento, bien puede sospecharse que los primeros federales excluidos (o autoexcluidos) son todos aquellos que pensaban que sus vidas no serían respetadas por los jefes triunfantes, o bien entendían que no valía la pena intentar una probable reinserción dentro del nuevo panorama político que se aproximaba. Éstos son justamente los casos que pueden detectarse en medio de las últimas batallas. En los momentos de declinación y oscuridad final, un grupo de federales consigue escapar por los techos de los edificios cercanos a la plaza. Los relatos de varios testigos hablan de más de 50 hombres. Entre los ejemplos más notables de los que deciden tomar ese rápido e incierto camino, figuran los nombres de José Agrelo y Manuel Pagola ${ }^{16}$.

¿Q ué ocurrió con los revolucionarios que decidieron moverse por otro andarivel? Los federales que finalmente fueron tomados prisioneros debieron someterse a los dictados de las leyes provinciales. La Junta, en la sesión del 6 de octubre, a pedido de Rodríguez, separa de

16 Véase por ejemplo, Carta de José María Roxas a Manuel José García, Buenos Aires, 15 de octubre de 1820, en Sal días 1988. Carta de Miguel Zañartu a Tomás Godoy y Cruz, 17 de octubre de 1820, Archivo Nacional 1949: 303 y 304 y De La Madrid 1947. 
sus cargos a los cabildantes que habían firmado el bando del día 2, designando en su reemplazo a individuos que estuvieran en perfecta sintonía con el nuevo orden. Así, se les inició un proceso ${ }^{17}$ a los capitulares Dolz, Isasi, Zavaleta, Villanueva y Videla. ${ }^{18}$ Paralelamente, comenzaron los procesos a los oficiales de los distintos regimientos que tomaron parte de la aventura callejera.

Los resultados fueron bastante positivos para los federalistas. Sustancialmente, porque en general aquéllos a quienes se les inició un proceso resultaron absueltos. Tal situación, sin embargo, no fue la misma para todos, ya que luego de recibir el dictamen del juez, los militares Salomón y Felipe Gutierrez, fueron rápidamente fusilados ${ }^{19}$. Según Carlos Heras, se trató de una medida ejemplar contra quienes se mostraron más violentos e intolerantes. Nuestros datos confirman esta afirmación. Salomón, por ejemplo, fue uno de los cabecillas de una de las tantas guerrillas urbanas presentes en los días del conflicto armado. Varios testigos lo identificaron como uno de los principales promotores del hecho revolucionario, pero también lo señalan dentro de aquellos que nunca abandonan el duro hábito de la hostilidad y la intransigencia. El agua de la exclusión parece mojar de este modo los pies de los federales más exaltados.

Los intentos de inclusión parecen ser más importantes. Tal situación puede advertirse mejor si nos detenemos a examinar qué sucedió con otros individuos que de un modo u otro participaron en esos días de "revolución". Conviene analizar ahora, entonces, cuáles son los requisitos de la señalada retórica de conciliación lanzada por los medios oficiales.

\section{Un solo partido: la retórica de la conciliación}

“U námonos, compatriotas, hagamos una sola familia, seamos virtuosos, y procuremos que otros lo sean a la fuerza, sino no lo quieren por bien, hagamos respetable y duradero el gobierno....y entonces serenarán las borrascas que han agitado la nave política

17 Para ello se nombró una comisión compuesta por Manuel Antonio Castro, J osé Cayetano Pico y Miguel Irigoyen, que debía formar causa y sentenciar en el término de veintedías. Al díasiguiente, laj unta amplió las facul tades deesta comisión para queiniciara una pesquisa, con el propósito de averiguar quiénes fueron los verdaderos promotores del tumulto del 1 al 5 .

18 Acuerdos del Extinguido Cabildo... ob. cit., sesión del 7 deoctubre de 1820.

19 Véase “Vindicta Pública”, La Gaceta, 18 de octubre de 1820. 
Fabián Herrero

del estado. M as si entre nosotros hay alguno, como ha habido en tiempos anteriores, que quiera erigirse en tribuno de la plebe y acomodar la anarquía y el desorden a su fines particulares...que tiemble..."

Estas palabras, escritas en un diario proclive al poder restaurado, señalan con entera certeza como rápidamente se dibujó una línea de clara separación entre radicales (o anarquistas) y moderados (o amantes del orden). Se trata, en definitiva, de excluir a los que perturban el ordenamiento legal y de unirse a los fragmentos políticos que no están incluidos dentro del nuevo tiempo político. Este tipo de argumento debe necesariamente asociarse con los vocablos y los gestos de reconciliación promovido por los responsables del poder provincial.

A decir verdad, dicha trama discursiva no dejó de desplegarse por esos días. Atravesó no sólo las columnas de los diarios que apoyaron a las auto ridades restituidas, sino también los documentos escritos tanto por el jefe militar de mayor significación como del propio gobernador. Veamos algunos testimonios. El ocho de octubre, a través de un encendido manifiesto, Martín Rodríguez se dirigió a los habitantes de la provincia. En este papel sobresalen varias cuestiones. Como es habitual en esta clase de escritos, sus primeras expresiones fueron de agradecimiento por los servicios prestados por todos los vecinos a quienes no por casualidad Ilamaban los "amigos del orden". Seguidamente contesta los cuestionamientos que provenían del sector federal. Esas críticas de signo negativo apuntaban directamente a señalar que el gobernador actuaba detrás de las filas políticas de los directoriales. De hecho, en menor medida también se lo acusaba de pertenecer a otros agrupamientos políticos de corte federalista.

En ese marco de cuestionamiento e impugnación, tampoco es casual entonces que el primer mandatario provincial se apresure a definirse como un hombre ajeno a cualquier facción. "Yo no pertenezco a facción alguna", sostiene el primer mandatario, y, luego, tratando de aclarar un poco más las cosas afirma en tono enérgico y contundente: "soy partidario del bien de mi patria, soy enemigo de los que tratan de arruinarla..." 21 .

20 "Prospecto.", Legión del Orden o Voz del Pueblo, sin fecha. Sobre esta línea temática véase, "Interior", El Imparcial, 19 de diciembre de 1820. "Era Nueva”, El Imparcial, número 1, 19 de diciembre de 1820.

21 "El gobierno al Pueblo", La Gaceta, 11 de octubre de 1820. 
En el mismo sentido, desmiente cualquier tipo de adhesión o simpatía por los contingentes de López, Carrera y Alvear, y, especialmente, de la facción directorial. "Ellos -se refiere a los vencidos- me incluyen en la que Ilaman facción de Pueyrredón. Son muchos los hombres que han servido diversos destinos en la anterior administración directorial del Estado y solamente el atrevimiento de la inquietud puede calificarlos a todos delincuentes..."22.

Como puede apreciarse, tanto federales como centralistas perciben a los partidos y a las facciones como vocablos intercambiables, constituyen un mal forzosamente, en la medida que como señala Sartori perturban el bien común (Sartori 1992:17-23). No obstante, mientras los primeros no hacen ningún tipo de diferencias, respecto a los segundos, en este caso a partir de la defensa de Rodríguez, se puede observar cómo distingue a los que han actuado de modo faccioso de aquellos a los que no puede colocarles el rotulo de simples delincuentes. En este sentido, es posible señalar dos cuestiones: Rodríguez no puede desvincularse del Directorio caído, el cual se encuentra totalmente desacreditado, así, su intención es mostrar que no todos actuaron de un modo incorrecto y reprochable. En segundo lugar, apunta a rescatar a los hombres que lo apoyan y que también tuvieron un pasado de adhesión y simpatía por aquel gobierno. Los que se pretende incluir en la nueva política de reconciliación son hombres que han prestado buenos servicios en el pasado.

Estos son los planteos básicos del primer mandatario provincial. Su manifiesto, como es habitual en este tipo de escritos que pretenden precisar las líneas de la política a seguir y buscan encender la chispa de la pasión patriótica, se cierra con un enérgico llamado a la unión moral y física de todos los habitantes para restituir "la patria a su pasado esplendor" (Sartori 1992:17-23).

Con este mismo espíritu, Juan M anuel de Rosas, dos días después, y con el permiso del gobernador, publicó una larga proclama que como advertimos disgustó al padre Castañeda. En ella explica al pueblo su conducta, narra su actuación pública y termina haciendo un ferviente llamado al orden: "O dio eterno a los tumultos! Amor al orden! Fidelidad a los juramentos! O bediencia a las autoridades constituidas!"23.

22 “El gobierno al Pueblo", La Gaceta, 11 de octubre de 1820.

23 "Manifiesto del coronel de caballería, comandante del 5to regimiento de campaña, al muy benemérito pueblo de Buenos Aires. Buenos Aires, 10 octubre de 1820. J uan Manuel de Rosas" (Bilbao 1919:121-125). 
Sobre esta base, promociona abiertamente la unidad de todos los ciudadanos y especialmente de todas las brigadas cívicas. De esta forma reconocía a los que en la más reciente aventura revolucionaria lucharon a favor del Gobernador pero también a quienes lo habían hecho en su contra. Su actitud bien podía leerse como una suerte de apuesta que indicaba que más allá de los enfrentamientos y las perdidas humanas, aún lo sostenía la esperanza de que los gestos y las acciones de conciliación podían ofrecer, por cierto, un dique y un cauce a los males de los conflictos armados.

¿Q ué tienen en común todos estos escritos? Los tres testimonios descriptos hasta aquí proponen una misma idea: en el horizonte político bonaerense no debe haber facciones, por el contrario, la unión de todos los porteños debe permitir la emergencia de un único partido del orden: el del gobierno y el de las leyes de la provincia. Se trata de una retórica de conciliación que tiene como una de sus intenciones dar tranquilidad a los distintos sectores políticos y al mismo tiempo, ofrece señales precisas de cuáles son las mínimas reglas que son necesarias respetar para efectivamente integrar la nueva realidad política.

Ahora bien, una de las formas de comprender las actitudes del gobierno proclives a la reconciliación, es analizando cómo las nuevas autoridades porteñas reorganizan las fuerzas de la provincia, en cuanto resulta una buena manera de entender su alcance y sus límites.

\section{La reorganización de las fuerzas armadas y los intentos de reconciliación}

Pues bien, luego de la irrupción federalista ¿qué regimientos se suprimen y cuáles se crean $?^{24} \mathrm{~A}$ través del llamado Departamento de Guerra "quedó ordenado" el siguiente "plan"25: el Regimiento de Dragones de línea y cuerpo de blandengues de esta frontera, a partir de ahora "queda extinguido" ${ }^{26}$. Sus individuos, de "sargento inclusive

24 "Departamento de la Guerra. Buenos Aires, noviembre 1 de 1820.", La Gaceta, 8 de noviem bre de 1820.

25 "Departamento de la Guerra. Buenos Aires, noviembre 1 de 1820.", La Gaceta, 8 de noviembre de 1820.

26 "Departamento de la Guerra. Buenos Aires, noviembre 1 de 1820.", La Gaceta, 8 de noviem bre de 1820. 
que se hallen en esta capital, serán incorporados desde hoy, al cuerpo de húsares de Buenos Aires"27.

La Brigada de Artillería desaparece y por el momento únicamente tendrán funciones activas en un solo batallón ${ }^{28}$. El Fijo, se dice también en un tono terminante, queda "borrado de la lista del ejército", ${ }^{29} \mathrm{en}$ adelante "se reconocerá por el 1 de Infantería de línea". Por su lado, el 1, 2 y 3 tercios cívicos formarán un Regimiento de Infantería de tres batallones con la planta que está detallada a los de línea. Su nombre de ahora en más "será el de la Legión Patricia"30.

En esta verdadera reestructuración de las fuerzas, saltan a la vista rápidamente varias cuestiones que revelan claramente los cambios que se producen en el área del ejército al término de la lucha de facciones. Es en primer término una de las medidas iniciales tendientes a adecuar el ejército a la nueva situación de autonomía provincial, la cual se inscribe en un marco obviamente mayor, en donde como señala Carlos Cansanello "se anuló la estructura de mandos heredada del Directorio y se la reemplazó con la Inspección General de la Provincia, la que con la eliminación de los cabildos, recibió también la jefatura de milicias" (Cansanello 2003:75-76). Esa institución provincial tuvo la capacidad de movilizar todas las tropas, fueran éstas de línea o de milicias. Así, pudo obtener "el monopolio del poder militar, que completó con el mando sobre la policía, en manos del Ministro de Gobierno" (Cansanello 2003:75-76). La reforma señalada, de este

27 “Departamento de la Guerra. Buenos Aires, noviembre 1 de 1820.", La Gaceta, 8 de noviembre de 1820.

28 "La plana mayor constará de un comandante, un sargento mayor, un primer ayudante, uno segundo, un subteniente de bandera, un capellán, un cirujano, un tambor mayor, y otro de ordenes. En la próxima revista de comisario se presentara este cuerpo bajo el plan que queda ordenado." "Departamento de la Guerra. Buenos Aires, noviembre 1 de 1820.", La Gaceta, 8 de noviembre de 1820.

29 "Sólo debe recordarse la denominación, que tenia, en los cargos, que se hagan a los oficiales, que se están causando por su complicidad en el tumulto desde la noche del 1 al 5 del pasado." "Departamento de la Guerra. Buenos Aires, noviembre 1 de 1820.", La Gaceta, 8 de noviembre de 1820.

30 "Las plazas de sueldo y plana mayor, serán las siguientes. Un coronel veterano, un teniente coronel idem, comandante del ler batal lón, dos tenientes coroneles sin sueldo, comandantes del 2 y 3 batallón, un sargento mayor veterano con suel do, un porta bandera por batall lón, sin suel do, un sargento 1 , un cabo 1 , dos 2 , y un tambor por compañía con sueldo y un tambor mayor y otro de ordenes con sueldo. La fuerza en el 1 y 2 batallón no excederá de cien plazas... El coronel Blas J osé de Pico es el nombrado para el arreglo y mando de esteregimiento y para que llegue a noticia de todos, publíquese por bando". "Departamento de la Guerra Buenos Aires, noviembre 1 de 1820.", La Gaceta, 8 de noviembre de 1820. 
modo, es una de tantas reformas que permitieron la centralización del poder de las fuerzas armadas de la provincia.

Se trata, en segundo lugar, de desmovilizar o bien de achicar el conjunto de hombres que la forman. Esta es una de las opciones que siempre aparece en los momentos posteriores a la superación de una crisis política. En días intensos, la fuerza militar crece de manera desproporcionada debido a que su actuación resulta necesaria para enfrentar conflictos exteriores, como los enfrentamientos con otras provincias, o bien para dirimir las colisiones producidas en el contorno de la política local. Terminado el periodo de confrontación y crisis, surge una nueva necesidad: la de desmovilizar precisamente esas fuerzas que exceden en demasía los gastos del estado. La cuestión no siempre resulta sencilla, ya que se intenta dar de baja a una parte de los sujetos que ayudaron a la consolidación del nuevo orden. Tulio Halperin Donghi ha planteado la complejidad de esa escena política en Buenos Aires. Las dificultades que tuvo, por ejemplo, Juan Manuel de Rosas, hacia fines de los años veinte para desmontar un contingente militar que le había permitido a la vez vencer a las fuerzas de Juan Lavalle y acceder al poder provincial ${ }^{31}$.

U na tercera cuestión es la que alude particularmente a la desaparición de algunas secciones militares, en cuanto no se suprime al azar cualquiera área, sino que se eliminan básicamente los cuerpos militares que adhirieron a la revolución: los tercios cívicos y el fijo.

Justamente en este preciso sentido, tales modificaciones, como es de esperar en este tipo de reformas, plantearon dudas y ciertamente abrieron nuevos problemas. ¿Q ué actitud tomará el gobierno, se preguntan algunos porteños, con aquellos hombres que pertenecían al ejército y ahora quedan excluidos? La respuesta a este interrogante aparece, concretamente, en un oficio dirigido al coronel de la Legión Patricia. En él se afirma que "sobre la falta de destinos para varios oficiales de los extinguidos tercios cívico de esta ciudad, ha tenido a bien el gobierno proveer hoy lo que sigue...":

"Habiendo resultado sin acomodo en el nuevo arreglo de La Legión Patricia varios beneméritos oficiales de los extinguidos Tercios Cívicos de la ciudad, por haber sido reducidas en aquella a seis las catorce compañías de que estos constaban en su antigua

31 Sobre esta temática véase en particular, Hal perin Donghi 1982:169-170. Sobre el peso de las fuerzas armadas en el estado porteño en un período posterior puede consultarse Ratto 2003 y Garavaglia 2003. 
formación, teniendo presentes los importantísimos servicios que dichos oficiales han prestado al país, y los sacrificios que constantemente han consagrado a la felicidad común de nuestros conciudadanos...dándoseles por el coronel de la citada Legión Patricia gracias expresivas a nombre de este gobierno... deberá asegurarles como se le recomienda, se les haga entender por el mismo habérseles agraciado con el goce de fuero personal de guerra y uso de uniforme en sus respectivas clases militares, en las que deberán presentarse y ser agregados a la guardia de Buenos Aires, compuesta de oficiales retirados a los objetos del instituto de dicha guardia..."32.

Como puede apreciarse, quienes hicieron sacrificios y se consagraron a la felicidad común fueron efectivamente los que participaron de la revolución. Concretamente, entonces, se reincorporaron a varios oficiales sospechados de "sedición" y los que no fueron incluidos en ellas, se les concedió el privilegio y las ventajas de justamente disponer de "fuero personal de guerra y uso de uniforme en sus respectivas clases militares"33. El goce de fuero militar los alejaba de estar sometidos a la justicia ordinaria, y les permitía seguir moviéndose dentro del entramado legal de su propia institución. En este sentido, lograr ese goce y el uso de uniforme no constituía un gesto simbólico o una simple retórica, sino que como lo ha señalado Sara Mata para el caso salteño, en ese otorgamiento "está en juego un espacio de negociación importante en la configuración del poder" ${ }^{\prime 34}$. Tenerlo o no tenerlo, significa moverse dentro un terreno distinto al de los demás habitantes de la provincia, y su obtención, no se da obviamente por que sí, sino que se debe a un reconocimiento especial y concreto.

Pero éste no es el único beneficio obtenido por algunos de ellos. Por esos mismos días se reemplazan las compañías que mencionamos más arriba, y en la lista de los convocados aparecen los nombres de oficiales implicados en la intentona revolucionaria. Pero hay más aún.

32 “Departamento de Guerra”, La Gaceta, 15 de noviembre de 1820.

33 "Departamento de Guerra”, La Gaceta, 15 de noviembre de 1820. "Batal lón deArtillería de Estado de Buenos Aires. Propuestas de los nuevos oficiales que deben servir los empleos de Plaza Mayor y compañía que hoy tiene expresado". Archivo General dela Nación, SalaX, 11, 8,4. Guerra. Comisario deArtillería, 1820.

34 En el caso de Salta, continua sosteniendo la autora, "quienes ocuparon los puestos más destacados en la milicias fueron importantes propietarios de tierras que a través del fuero militar extendieron su poder sobre la población rural". Véase Mata de López en Herrero 2004:128. 
Varios de ellos, a su vez, aparecen con un grado militar superior al que tenían.

Los datos sobre el regimiento de la ciudad con relación a las reincorporaciones y bajas brindan al respecto precisos y valiosos indicios ${ }^{35}$. El 11 de noviembre de 1820, el coronel Dn. Manuel Ramírez, pide al gobernador sustituto que se aprueben los nombramientos de nuevos efectivos para la creación de un nuevo batallón a su cargo. Tales despachos son aprobados el 15 de noviembre. En ellos hemos detectado dos casos de oficiales que fueron revolucionarios en octubre y ahora son reincorporados y ascendidos en su grado militar: al Subteniente Dn. Cayetano Cortinas lo reincorporan como Teniente 2 do de la 3era. compañía y, al subteniente Dn. Francisco Machado, como Teniente 2 do de la 4 ta. Otros oficiales, asimismo, son reincorporados con el mismo grado militar: para Subteniente, al subteniente Dn Baltazar Borges y para Capitán de la 4ta., al capitán Dn Mariano Guinta ${ }^{36}$.

En esta misma línea, por otra parte, hallamos casos de revolucionarios que luego de ese conflicto siguen en funciones en las filas del ejército y ahora, junto con otros hombres que estuvieron en el gobierno, se les concede la licencia de su servicio por una enfermedad que no les permite continuar en sus $\operatorname{cargos}^{37}$.

Finalmente, como ya se ha advertido, otra forma de reconciliación es el puntual beneficio otorgado a uno de los jefes militares sublevados: Hilarión de la Q uintana. ¿En qué consiste? En el otorgamiento de un pasaporte dado por el gobernador para que pase a retiro en Colonia. Asediado por las críticas que el hecho provocó, Rodríguez debió explicar inmediatamente su conducta sosteniendo que tal actitud tenía como principal fundamento el cumplimiento de una promesa que,

35 Hay otros casos que aparecen mencionados, sin embargo, no podemos confirmar si en verdad participaron en la revolución. Para 2do Ayudante Mayor. A Dn. Juan Antonio Vazques que ha servido igual empleo en la extinguida brigada. Para Capellán, al presbitero Dn. Manuel Delgado que ha servido igual empleo en el regimiento. "Batal lón deArtillería del Estado de Buenos Aires. Propuestas de los nuevos oficiales que deben servir los empleos de Plaza Mayor y compañía que hoy tiene expresado." AGN, Guerra. Comisaría de Artillería. 1820. Sala X, 11, 8,4

36 AGN, Guerra. Comisaría deArtillería. 1820. SalaX, 11, 8, 4.

37 Así, el 13 de noviembre de 1820, el citado Coronel Manue Ramírez pide que se de licencia absoluta a los individuos que se encuentran mutilados: 2da Arts, Manuel Balaguer. Arroja sangre por la boca. 3eraArts, J osé Torres, una cicatriz en el hueso de la frente. AGN, Guerra. Comisaría deArtillería. 1820. Sala X, 11-8-4. 13 de noviembre de 1820. Coronel Manuel Ramírez...ob. cit. 
precisamente, le había formulado a dicho jefe militar en los días agitados del conflicto armado ${ }^{38}$.

La reestructuración de las fuerzas de la ciudad es un muy buen indicador de que la retórica de conciliación fue acompañada por algunas medidas políticas concretas de inclusión de aquellos que participaron en la revolución. De este modo, debe matizarse la idea de que estos cambios tuvieron como uno de sus fines la marginación política y militar de grupos políticos opositores.

Resulta oportuno examinar ahora, cuáles son los argumentos de la defensa de aquellos que son acusados de haber participado en el golpe y qué destino tuvieron.

\section{El principio de subordinación y la absolución de los sospechosos de haber sido revolucionarios}

Hay un argumento que, en el proceso iniciado a los sospechosos de haber participado en la intentona revolucionaria de octubre, es utilizado de manera casi unánime por los miembros de las filas militares: todos invocan en su defensa el "principio de subordinación". Significa que el acusado confiesa por un lado que ha participado en la revolución y sin embargo manifiesta, por otro lado, que no actuó de acuerdo a su forma de sentir y pensar sino que lo hizo obedeciendo estrictas y directas ordenes.

Fue el caso de Silvestre Millán, quien precisamente reconoció que tocó el tambor para la generala porque así se lo mandó su jefe, el capitán Dn Genaro Salomón ${ }^{39}$. Y éste último, según el mismo testigo, afirmó por su parte que no obraba por su propia voluntad sino que lo hacía obedeciendo exactas ordenes del Cabildo ${ }^{40}$. En sintonía con este razonamiento, Felipe Gutiérrez, por su lado, declaró que fue a la plaza e hizo fuego por orden del capitán D on Juan Balaguer y seguidamente aclaró que debió hacerlo por el simple hecho de que "estaba impuesto al servicio" ${ }^{41}$. Luego reforzó su argumento, al afirmar que en la plaza

38 "El gobierno al pueblo", La Gaceta, 11 de octubre de 1820.

39 AGN, Guerra. Comisaría de Artillería. 1820. Sala X, 11, 8, 4. Dedaración de Silvestre MiIlán...ob. cit.

40 Ibid.

41 AGN, Guerra Comisaría deArtillería. 1820. SalaX, 11, 8, 4. “Criminal. Contra el capitán del 2do tercio cívico D. Genero González Salomón...ob. cit Declaración de Felipe Gutiérrez, 10 de octubre de 1820. 
tampoco se movió de acuerdo a su criterio y de modo individual, ya que en todo momento "recibió órdenes del capitán Salomón y (de) Pagola"42.

En esta misma línea otro sumario, iniciado a varios oficiales, ofrece más evidencias al respecto. Se trata de un hecho un poco más confuso, debido a que son individuos que se cambian de bando en medio del combate. Son algunos sujetos que dependen en los primeros días de "la revolución" del Sargento Mayor Bonifacio Ramos. Sin embargo, cuando los representantes de ambos sectores enfrentados se hallaban parlamentando, dichos oficiales se unen a las fuerzas del gobernador, poniéndose a las órdenes del Capitán Torres ${ }^{43}$.

A hora bien, la cuestión que se plantea es dirimir si realmente participaron porque estaban de acuerdo con la causa de la revolución, o bien lo hacían porque recibían órdenes superiores por las cuales se sentían obligados a participar ${ }^{44}$.

Como se ha visto ya, los acusados sostenían la idea de que participaron siguiendo la natural cadena de mandos, sin embargo, el tribunal militar no encontró en un primer momento una respuesta precisa. Sus miembros, por este motivo, le envían una nota al gobernador sustituto, M arcos Balcarce, en la que señalan que luego de oír las declaraciones de los oficiales supuestamente implicados, no pueden aun sugerir un dictamen para que el gobernador finalmente dictamine. No obstante, sostienen que teniendo en cuenta que han participado de distintas formas en esos días, aunque no de manera decisiva, ya que lo hacen "por un principio de subordinación"; y considerando que "aun cumplen servicios y hacen falta", le solicitan al gobernador que "Ios sospechosos" sigan en sus puestos de trabajo, sosteniendo, que no hay todavía cargos concretos contra ellos ${ }^{45}$.

¿Qué sucedió posteriormente? Los acusados vuelven a sus unidades militares, ya que poco tiempo después el juez de la causa los

42 AGN, Guerra. Comisaría deArtillería. 1820. Sala X, 11, 8, 4.

43 AGN, Guerra. Comisaría de Artillería. 1820. Sala X, 11, 8, 4. "Sumario contra los oficiales de la extinguida Brigada de artillería, sargento mayor Dn Bonifacio Ramos...ob. cit., 17 de octubre de 1820, informe de Comandante General Mat́as I rigoyen al gobernador sustituto Marcos Balcarce, sobre la conducta de oficiales en las ocurrencias del primero de octubre de 1820 .

44 AGN, Guerra. Comisaría deArtillería. 1820. SalaX, 11, 8, 4.

45 AGN, Guerra. Comisaría deArtillería. 1820. SalaX, 11, 8, 4. 9 de noviembre de 1820. 
absuelve ${ }^{46}$. Como se ve, la utilización del principio de subordinación resultó un argumento relativamente eficaz. Pues bien, ¿a qué responde esta política de reconciliación? Es probable que en parte responda a la necesidad de lograr una base de mayor apoyo y adhesión, la cual resulta muy necesaria en un marco de crisis política. Los que protestan en octubre no es un grupo absolutamente minoritario, su integración al nuevo orden posibilitaría de algún modo el fortalecimiento del nuevo poder provincial. Por otra parte, no habría que olvidar las palabras de quienes que intervinieron en el juicio, me refiero a aquellos que alertaban al gobernador de que esos sospechados de revolucionarios hacían falta en el servicio de armas. Dicho elemento se tomó en consideración a la hora de dar una sentencia y de ningún modo parece ser extraño al mundo político rioplatense.

La necesidad de hombres para el ejército, ha señalado Juan Carlos G aravaglia, ya era sensible desde las invasiones inglesas de 1806 y 1807 y se acentuó desde 1810 cuando comenzaron a formarse los primeros ejércitos expedicionarios revolucionarios (G aravaglia 2003:161). En la misma línea, trabajos recientes han ido probando cómo los gobiernos provinciales, como el de Entre Ríos, tuvieron que elaborar diferentes estrategias para lograr constituir una fuerza militar, las cuales presentan instancias de negociación y consenso ${ }^{47}$. Una de ellas era el montaje de un mecanismo de funcionamiento que, frente a la imposibilidad de organizar un ejército regular y pago, combinaba tropas milicianas con otras provenientes de los cívicos (Schmit 2004:174). También se pudo constatar que en caso de delitos de militares poco graves, se tuvo en cuenta la necesidad de esos hombres tanto para la producción como para la guerra. En ese marco parece haber "operado una lógica que privilegió el apercibimiento y el disciplinamiento, sobre todo a través de aumentar las penas con recargo de más años de servicio al estado en las tropas de línea y no en la aplicación sistemática de castigos capitales" (Schmit 2004:174).

46 AGN, Guerra. Comisaría deArtillería. 1820. Sala X, 11, 8, 4. El juez Manuel Del Mármol de la causa los absuelve de todo cargo, el 21 de julio de 1821. Se trata de los cinco oficiales de la extinguida brigada de artillería, capitanes Dn Mariano Giunta, Dn José Díaz, y los subtenientes Dn Cayetano Cortinas, Dn Baltazar Borges y don Francisco Machado. Asimismo, el 15 de octubre de 1821, DoñaAngela Caree, "la mujer legitima deSurlin" pide quele de una graciaa su marido, pasó un año de su detención, está cansado y debido a los éxitos de la patria en Lima, pide que se le de la libertad. Posteriormente, el gobierno le da la libertad por decreto.

47 Véase el excelente libro de Schmit 2004:153-201, especialmente el capítulo 6, "Consenso y negociación en torno al cotidiano servicio de la guerra". 
Fabián Herrero

\section{Pensar "la revolución" dentro de la ley}

Concluidos los enfrentamientos armados, a los muy pocos días, surgen numerosas voces que intentan reflexionar sobre las recurrentes y odiadas revoluciones. El fin es claro: tratar de ofrecer algún tipo de respuesta que tenga el sabor de las cosas duraderas y definitivas. En las columnas de los diarios porteños tres cuestiones sustantivas se imponen a simple vista. En primer término, cuál es la naturaleza del acontecimiento, esto es, cómo puede definirse. En segundo lugar, se intenta mostrar que la falta de conocimientos de los porteños sobre el funcionamiento de las asambleas populares es uno de los elementos que contribuyen a la promoción de estallidos políticos como los recientemente vividos. La tercera cuestión se refiere a las atribuciones del Cabildo y a la falta de conocimientos que se tienen de ellos. Por este motivo, se considera oportuno informar sobre los requisitos esenciales de funcionamiento, ya que la sala capitular se ha visto comprometida en acciones violentas y políticas que no le competen.

La primera de ellas remite, por consiguiente, a la caracterización de la llamada "revolución federal". Desde La Gaceta, se define al acontecimiento como una sedición, ya que según las instituciones vigentes esas irrupciones violan precisamente las Ilamadas "leyes fundamentales", en cuanto usurpan y atropellan la soberanía del pueblo ${ }^{48}$. Esos alterados sujetos, entonces, no sólo con su acción "ofenden la vida" sino que además atentan directamente contra "la conservación del estado" ${ }^{\prime 4}$.

Visto de esta manera, el concepto de sedición es utilizado para calificar la aventura federalista, la cual resulta doblemente cuestionada. No es, en primer lugar, una acción legítima, debido a que fue provocada por un número reducido de individuos que actuaron de modo violento y sin respetar las leyes de la provincia. No es, en segundo lugar, un acto representativo del pueblo de Buenos Aires, ya que su escasa adhesión invalida una consideración en esos términos. Para decirlo con otras palabras: pareciera que, en el instante de esas movilizaciones, un fragmento de la sociedad quiere, ella misma, ser la expresión excluyente de lo que es el pueblo. En ese marco de emergencia de un grupo que pretende apropiarse de la voz popular, la fuerza que puede

48 "BuenosAires", La Gaceta, 11 de octubre de 1820.

49 "Buenos Aires", La Gaceta, 11 de octubre de 1820. 
quebrar esa resistencia es el respeto de las leyes de la provincia, elaboradas y sancionadas por sus propios y legítimos representantes.

Otra cuestión que se plantea es distinguir cuándo precisamente una reunión popular debe ser incluida dentro del marco legal y cuándo, por el contrario, se transforma en un acto ilegal, es decir, en una sedición o en un tumulto. Aquí el discurso directorial se dirige de modo particular a los ciudadanos menos ilustrados. En la falta de ilustración de una franja muy importante de porteños, encuentran, justamente, una de las causas de todos los alzamientos políticos ocurridos luego de 1810. A ese vasto público, entonces, tratan de explicarles (lo más detalladamente posible) las diferencias existentes entre las asambleas populares y los tumultos.

La instrucción, de esta forma, es una pieza clave que regula cualquier tipo de "tensión democrática" (Rosanvallon 1999:163). Cualquier mal entendido debe ser respondido bajo las premisas de una ilustración básica sobre los temas de interés colectivo. Los hombres no se mueven por cualquier lugar del modo que mejor les parezca sino que deben actuar de acuerdo a determinados y precisos criterios comunes. El ciudadano actúa bajo ciertas reglas. En este sentido, como señala con certeza Pierre Rosanvallon debe identificarse "al ciudadano como un actor racional" (1999:163).

Desde este supuesto, la prensa justamente juega un papel didáctico fundamental. En las páginas de las publicaciones periódicas, como ha señalado precisamente Francois-Xavier Guerra, se trata de poner en obra una "estrategia gradual" (Guerra 2000:234) con el fin de ir imponiendo lentamente las ideas que se consideran justas y adecuadas. Pues bien, ¿cuáles son esas ideas que los directoriales pretenden que sean justas y adecuadas para todos? Sustancialmente, debe comprenderse cuál es el espacio público en el que cada uno puede expresarse, esto es, cuando puede convocarse a una asamblea popular y quien puede hacerlo. Habría que diferenciar aquí las asambleas legales de las asambleas ilegales. En la primera, se convoca y se reúne a los ciudadanos en el tiempo y en el lugar que marcan las leyes, con el claro propósito de tratar o deliberar sobre algunos de los "negocios de la República" 50 . Por el contrario, en la segundo, los ciudadanos, o los que no lo son (la aclaración resulta importante), se congregan clandestinamente sin una convocatoria legal y lo hacen en horas y sitios que

50 “Tumultos”, La Gaceta, 18 deoctubre de 1820. Véasetambién, “Administración dejusticia”, La Gaceta, 15 de noviembre de 1820. 
la ley no les señala, con la pretensión de "resolver estrepitosamente en los negocios públicos"51. Este último aspecto es repetido casi de manera machacona. El pueblo soberano sólo debe deliberar en las formas legítimas que el marco legal de la provincia determina. Esa deliberación, por consiguiente, debe realizarse sin recurrir a ningún tipo de violencia. "Toda otra reunión, concluye el escritor del diario oficial, es sediciosa y tumultuaria"52. Q uienes participan en esas reuniones transforman ese espacio público en una arena de gladiadores donde todo vale. En estas circunstancias, los hombres hacen un extraño y peligroso pasaje al lado oscuro de la confusión y el caos. Por este motivo, las asambleas de carácter popular no deben hacerse de cualquier forma, sólo puede permitirse la realización de aquellas que las leyes determinan y admiten.

En la visión directorial, las sediciones son percibidas como un "delito" de extrema gravedad por cuanto "el Estado se pone en guerra con los mismos que deben sostenerlo"53. Esos odiados movimientos, una vez que se ponen en marcha, no hacen otra cosa que producir el choque entre dos o más poderes del Estado. Éste es precisamente el tercer punto en el que quisiera detenerme y reflexionar.

¿Cuáles son esas autoridades que se enfrentan política y militarmente? Son aquellas que se enfrentaron en octubre. Es claro que sobre esta base debe entenderse también el oficio que el gobernador dirige a la Junta de Representantes, en el que afirma que "sería muy del caso que estos cuerpos (el Cabildo) no reconociesen otra autoridad que la del gobierno, para que cesase el choque a que alienta la división del poder" ${ }^{\prime \prime 5}$.

51 "Tumul tos", La Gaceta, 18 de octubre de 1820.

52 “Tumultos", La Gaceta, 18 deoctubre de 1820.

53 "Tumultos", La Gaceta, 18 deoctubre de 1820.

54 Acuerdos de la Honorable J unta de Representantes... ob. cit, Sesión 6 de octubre de 1820. Veamos otros ejemplos. En las sesiones de la J unta de Representantes en los momentos de la revolución se muestra a dos bandos enfrentados, por un lado, "Ios jefes de oposición" y por otro "al gobernador". Acuerdos de la Honorable J unta de Representantes... ob. cit., Sesión 4 de octubre de 1820. Luego de la revolución, aun se menciona a los bandos enfrentados como dos autoridades diferentes, aunque, ahora se sostiene que los alzados tienen menos representación. Así, comienza la sesión aclarándose que la junta sigue ahora en sus funciones luego que el gobernador reconquistara el orden, enfrentándose "contra los que han practicado un Partido revolucionario apoyado en la autoridad y representación de una parte pequeña del Cabildo que han turbado la tranquilidad pública... desde el domingo 1 del corriente hasta el día de ayer a las seis". Acuerdos de la Honorable J unta de Representantes... ob. cit. 
Esta idea aparece también en la prensa oficial. El problema radica en que las autoridades de Buenos Aires no parecen tener en claro cuáles son sus verdaderas funciones.

Para ilustrar esta particular situación, es útil mencionar una comunicación publicada en ese diario y firmada por "El patriota reflexivo y consternado". En ella se intenta diferenciar las funciones del Cabildo y de la Junta de Representantes ${ }^{55}$. El incógnito autor comienza su planteo destacando a "la altamente respetable Autoridad del Cabildo" por su representación, por las nobles funciones de administración, de justicia ordinaria, policía, defensoría de menores, la de pobres", entre otras. Pero luego se pregunta

“CCómo puede compararse...ésta Autoridad subalterna (se refiere al Cabildo) con la soberana representación de la Junta destinada a dar la ley y la regla, a que deben ajustarse no solamente las funciones de toda otra Autoridad, más aun su misma elección y nombramiento, y por consiguiente a ser respetada y obedecida por todas como la primera y la fuente de donde emanan?"156.

El Cabildo, en efecto, no puede encaminarse hacia ninguna revolución, debido a que concretamente no tiene una misión política específica que cumplir. Por este motivo, una de las dificultades más graves radica en que cada tanto se presentan violentando las calles y la plaza de la ciudad "una clase de hombres armados que no están bajo la absoluta dependencia del poder ejecutivo" 57.

Reforzando su argumento, en esta precisa línea, considera que la respuesta para evitar

“el despotismo no conoce el derecho ni la política otra fuerza que la moral con que arma los poderes intermedios y el pueblo

55 “... el objeto de la prensa libre es restituir al pueblo y rectificar sus opiniones: parece que la que tienen al gunos ciudadanos sobre la autoridad y funciones de la J unta y la del Cabildo, es equivocada. Esta equi vocación ha tenido sin duda gran parte en las frecuentes revoluciones que nos han conducido hasta el deplorable estado presente que los aspirantes, los descontentos y lo que aparecen río revuel to a toda costa, han sabido aprovecharse de ella por derribar las autoridades y dar en tierra con nuestras instituciones." "Señor editor de la Gaceta Ministerial", La Gaceta, 25 de octubre de 1820.

56 "Señor editor de la Gaceta Ministerial", La Gaceta, 25 de octubre de 1820.

57 Para cortar en seco con la irrupción tumultuosa, con el choque deautoridades, como es el caso del Cabildo y el Gobernador, "los poderes subalternos (se refiere al primero) deben depender del poder ejecutivo". "Señor editor de la Gaceta Ministerial", La Gaceta, 25 de octubre de 1820. 
mismo, porque no hay cosa más temible ni origen más fecundo de convulsiones y de espantosa anarquía que dos poderes de tendencia contraria armados de fuerza física cuyo conflicto y choque es tan fácil en cada momento" ${ }^{\prime \prime 58}$.

Como se ve, llega a la misma conclusión que el gobernador. En línea con esta idea, en el diario oficial se afirma que el ayuntamiento, "no es un poder, ni puede ejercer actos potestativos, sino económicos y municipales" 59 . Un Cabildo, continúa, representa a "una ciudad, a una villa, pero no a un estado"60. El de Buenos Aires, de este modo, representa al pueblo de este lugar pero no a la provincia, y los representa como "súbdito y no como soberano"61. Cabildo Gobernador, concluye, es "la implicancia más absurda" ${ }^{2}$. El problema entonces de las revoluciones radica en que se confunden las atribuciones del cuerpo capitular, adjudicándole, concretamente, una dimensión política que no tiene ${ }^{63}$. Esa equivocada función política del Cabildo hace que sus miembros se crean con derecho a irrumpir por la fuerza por encima de cualquier otra autoridad provincial.

Llegados a este punto, conviene que examinemos un instante dos cuestiones particulares. La primera, si la actitud centralista con relación al ayuntamiento es nueva o tiene su historia en la provincia y la segunda, determinar si realmente el Cabildo tuvo una dimensión política de tanta significación como se le adjudica aquí.

58 "Señor edi tor de la Gaceta Ministerial", La Gaceta, 25 de octubre de 1820.

59 "Reflexiones. Sobre la exactitud de los principios sociales y sobre los vicios que pueden alterarlos", La Gaceta, 25 de octubre de 1820.

60 "Reflexiones. Sobre la exactitud de los principios sociales y sobre los vicios que pueden alterarlos", La Gaceta, 25 de octubre de 1820.

61 "Reflexiones. Sobre la exactitud de los principios sociales y sobre los vicios que pueden alterarlos", La Gaceta, 25 de octubre de 1820.

62 En este sentido, aclara, "regístrense las leyes antiguas de su establecimiento: examínense las leyes y reglamentos patrios desde e año 1810: léanse sus especiales ordenanzas y no se señalara una sola, que le atribuya la sucesión del gobierno que tantas veces se ha abrogado." "Reflexiones. Sobre la exactitud de los principios sociales y sobre los vicios que pueden alterarlos", La Gaceta, 25 de octubre de 1820.

63 "Reflexiones. Sobre la exactitud de los principios sociales y sobre los vicios que pueden alterarlos", La Gaceta, 25 de octubre de 1820. 


\section{La dimensión política del Cabildo y la actitud previa de los centralistas}

Después de la revolución, el Cabildo de Buenos Aires conservó el ejercicio de las funciones políticas que le eran propias. La trayectoria de esa actuación la conocemos bien a partir del clásico trabajo de José M aría Sáenz Valiente ${ }^{64}$. En término generales, el cuerpo capitular mantuvo su carácter de órgano representativo del pueblo, y en este preciso sentido, conservó las dos prerrogativas o funciones extraordinarias que ejercía durante el período de dominio español: convocar al pueblo en Cabildo abierto y asumir el gobierno en caso de acefalía. A estas atribuciones típicamente políticas, agregó otras que tenían características similares que, pese a su carácter de organismo local, lo convirtieron en factor preponderante o decisivo en el desarrollo de los acontecimientos políticos y en la organización de los poderes de la Nación o de la provincia ${ }^{65}$.

Para comprender mejor dicha dimensión política resulta conveniente conocer algunos aspectos relacionados con los episodios en donde se producen acefalías pero también cuando se convocan e instalan las reuniones populares. Empiezo por ésta última.

Los Cabildos abiertos de la época colonial eran asambleas deliberantes, las cuales debían ser convocadas con autorización gubernativa por el Cabildo ordinario quien además las presidía. Los habitantes de Buenos Aires no fueron, por cierto, sus principales asistentes, ya que por lo general solo podían concurrir aquellos que eran invitados de modo particular. Esos vecinos eran los denominados vecinos calificados.

A decir verdad, su maquinaria organizativa no era uniforme. Durante la primera mitad del siglo XVII fueron verdaderas asambleas populares a las cuales concurrían los vecinos y donde no faltaban los

64 En la redacción de la parte correspondiente a las atribuciones políticas del Cabildo de Buenos Aires he consultado el detall lado trabajo de Sáenz Valiente (1952:163-189).

65 Hasta el año 1820, Buenos Aires fue de hecho la capital delas Provincias Unidas del Río de la Plata y recién a raíz de los sucesos de comienzo de ese año, vino a quedar reduci da a un simple gobierno deProvincia. Por su carácter de ciudad iniciadora y orientadora del movimiento revolucionario, Buenos Aires tuvo en su Cabildo, no solamenteel punto de apoyo de las aspiraciones popul ares, legítimas o no, sino también las primeras manifestaciones de gobierno propio, porque a partir del año 1816, la corporación se renovó popularmente mediante el sistema de segundo grado, con intervención de la población rural, primero, sin participación de ella, más tarde. El Cabildo adqui rió así el carácter de una verdadera legisl atura local y fue el precursor de la Junta de Representantes que lo extinguiría como institución incompatible con ella (Sáenz Valiente 1952:164). 
tribunos del pueblo. Con el paso del tiempo, sin embargo, la llamada gente decente fue su único y exclusivo protagonista. Los Cabildos abiertos del siglo XVIII revistieron este último carácter. Los celebrados en los años finales del régimen colonial fueron restringidos en cuanto a la calidad de los componentes: el realizado el 14 de agosto de 1806 se verificó con asistencia de las corporaciones y "personas condecoradas del estado militar y civil", y el efectuado el 22 de mayo de 1810 tuvo análogo carácter; el permiso solicitado por el Ayuntamiento se refería a "la principal y más sana parte del vecindario", y el Virrey Cisneros al autorizarlo destacó que la invitación debía comprender tan sólo a los "vecinos de distinción" (Sáenz Valiente 1952:163-189).

Los Cabildos abiertos posteriores a la Revolución presentan características propias que los diferencian de los realizados durante la época colonial. Unos fueron simples reuniones de funcionarios; otros, actos electorales, a los cuales no resulta apropiado aplicarles la clásica denominación. Por lo general, fueron reuniones o asambleas del pueblo, impuestas por éste sin previa convocatoria, o las convocaron las autoridades. La convocatoria fue extraña, en ocasiones, al Cabildo y partió directamente del Superior Gobierno. La presidencia, que tradicionalmente correspondía al Ayuntamiento, no siempre fue ejercida por éste, sustituido en ella, unas veces por el gobernador intendente, otras por uno de los alcaldes. En la mayoría de los casos los asistentes concurrían de modo voluntario, pero en algún caso tuvo carácter de obligatorio. A hora bien, ¿cuál fue el lugar de reunión? Las cosas no se modificaron demasiado. Se conservó la costumbre de reunirlos en el recinto del Cabildo o en el interior de una iglesia, tal cual ocurría en la época colonial.

Como se ve, el Cabildo fue una pieza clave para la consulta del pueblo en caso de crisis políticas y su actuación fue igualmente importante en caso de acefalía. En este último sentido, no debería causar sorpresa que el Cabildo de la etapa colonial, al atribuirse a sí mismo la representación popular, se sintiera facultado para asumir el gobierno político cuando se producían casos de acefalía. De hecho, la ley no determinaba cuál era el reemplazante legal de la autoridad faltante, ausente 0 impedida.

Más tarde, durante los años posrevolucionarios, el Cabildo de Buenos Aires puso en ejercicio esta facultad extraordinaria en varias ocasiones. Es lo que ocurrió justamente en el Cabildo abierto o Congreso General del 22 de mayo de 1810. Los ciento cincuenta y cinco 
votos pronunciados por la cesantía del Virrey se inclinaron también en el sentido de que el Cabildo asumiese el mando, pero no hubo uniformidad en cuanto al tiempo en que lo ejercería, ni a las atribuciones que se le conferían y si tendría o no voto el Síndico Procurador General. Lo cierto es que, proclamado el escrutinio practicado por el ayuntamiento, éste asumió el gobierno con el título de Excelentísimo Cabildo Gobernador ${ }^{66}$.

En esta oportunidad, la asunción del gobierno respondió a la voluntad del Cabildo abierto. En otras ocasiones, se hizo a partir del requerimiento popular. La primera de ellas tuvo lugar el 12 de octubre de 1812, en el marco de un estallido revolucionario, el Cabildo, como ocurrió con anterioridad, actuó al solo efecto de constituir el gobierno. Todo volvió a repetirse con la revolución del 15 de abril de 1815; el ayuntamiento, bajo la presión de los acontecimientos, se hizo cargo del gobierno de la provincia, y los acuerdos celebrados entre el 18 de abril y el 6 de mayo, excepción hecha del realizado el 25 de abril, aparecen encabezados con el nombre de Excmo. Cabildo gobernador o Exmo ayuntamiento gobernador.

Durante el año 1820, esta situación se repitió en cinco oportunidades. El Cabildo, convertido en poder político de extraordinaria gravitación, comenzó por asumir el mando de la provincia desde el 11 al 12 de febrero, con motivo del requerimiento formulado por los jefes y oficiales del Ejército Exterior, de la disolución del Congreso y de la renuncia del Director Rondeau. El 11 de marzo, el 20 de junio, el 30 del mismo mes y finalmente el 2 de octubre, el Cabildo ejerció transitoriamente el gobierno prestándose, en ocasiones, a servir de instrumento a intereses personales 0 a las facciones en lucha.

Llegados a este punto resulta oportuno hacer una última pregunta. ¿El Cabildo tuvo además otras formas de intervención pública? A decir verdad, muchas de ellas estuvieron ligadas a la sanción del estatuto provisional de 1815, entre otras, la formación del Registro cívico, el Registro de las cartas de ciudadanía y otorgamiento de las mismas, el relevamiento de la condición de prisioneros, la autorización de expediciones militares y medidas fiscales o la suspensión de garantías

66 En este sentido, Sáenz Val iente aclara que la actuación del Cabil do en esta emergencia no respondió, por cierto, a la expectativa popular, pues excediéndose en sus atribuciones no vaciló en constituir una J unta bajo la presi dencia del Virrey depuesto. Esta actitud le val ió la repul sa del pueblo y la imposición por éste de las personas que constitui rían el nuevo gobierno, sin perjuicio de las atribuciones de vigilancia y contral or que el Ayuntamiento se reservó y provocaron la destitución de su miembros electivos. 
constitucionales ${ }^{67}$. A modo ilustrativo destaco particularmente una de ellas: el veto de las leyes dictadas.

El Estatuto Provisional confería al Cabildo el derecho de enervar las sanciones legislativas en unión con el Directo. Según el artículo VIII, toda adición o corrección de las leyes vigentes, como igualmente todo nuevo reglamento que se dictara, no podía publicarse, y por consiguiente no entraba en vigencia sin la previa consulta al Gobierno y al Cabildo, que disponían de ocho días, a más tardar, para manifestar su consentimiento o disenso, debiendo expresar, en este último caso, las razones fundamentales de la oposición. La consulta debía hacerse en primer término al Gobierno y, formulado el disentimiento, la Junta pasaba la ley a estudio del Cabildo. Si éste se manifestaba conforme con ella, su conformidad anulaba el disentimiento del Poder Ejecutivo y la ley debía publicarse. En caso contrario, es decir, si el Cabildo estaba de acuerdo con el disentimiento manifestado por el Poder Ejecutivo y disconforme, por lo tanto, con la ley sancionada, ésta quedaba sin efecto. La coincidencia de ambas autoridades en contra de la ley importaba el ejercicio de un veto absoluto. En este marco, señalado en el artículo IX, si Gobierno y Cabildo aprobaban la ley o la consentían, dejando vencer el término para oponerse a ella, la publicación se realizaba de inmediato.

En suma, el Cabildo tuvo atribuciones políticas de verdadera significación, las cuales no son producto directo del hecho revolucionario sino que tienen un pasado más largo que remite a la etapa de dominio colonial español. No obstante, esas intervenciones públicas se profundizaron enormemente luego de los cambios producidos a partir del año 1810. Por todo lo dicho hasta aquí puede comprenderse mejor porqué los centralistas no se equivocaban cuando sostenían que uno de los factores que contribuían a la gestación de los estallidos políticos radicaba en que el ayuntamiento hacía valer iniciativas políticas que en realidad no le correspondían, sino que se concretaban y materializaban como cuestiones de puro hecho.

A hora bien, esta actitud adoptada por los centralistas es a mi juicio relativamente reciente, ya que durante el decenio revolucionario fueron precisamente grupos ligados a esas creencias los que dispusieron de los resortes políticos del Cabildo local. Y si bien es correcto

67 Los detalles de estas atribuciones son detalladamente explicadas por Sáenz Valiente 1952:180185. 
que antes de esa fecha hubo críticas, las mismas nunca fueron tan terminantes como lo son ahora68.

El Cabildo de Buenos Aires jugó políticamente del lado de los sectores que manifestaban una orientación de poder centralista entre los años 1810 y 1819. En ese cuadro, anoto dos ejemplos puntuales. La caída del Directorio de Carlos Alvear contó con el apoyo del ayuntamiento porteño, que, por esos días, frente ese clima de cambio y desorientación, figuraba como Cabildo gobernador. Un mes más tarde, de ese Cabildo surge una nueva estrategia de poder de centralización de poder. Confirman ese nuevo camino, tanto las instrucciones otorgadas a los diputados que insistían en la construcción de un estado de características nacionales único e indivisible como la designación de un nuevo Directorio.

Debe recordarse, en segundo término, que una de las causas que produjo la tendencia confederacionista de junio de 1816 fue el choque producido entre diferentes autoridades de poder en Buenos Aires. Dentro del contingente confederal, figuraban el Director Interino y el gobernador intendente, mientras que el Cabildo y la Junta de $O$ bservación adherían a la propuesta centralista. No es casualidad que los federal es comienzan a tener mayor ingerencia en el Cabildo cuando éste, a comienzos de 1820 luego del derrumbe del régimen directorial, deja de tener importancia en los negocios nacionales y debe encerrarse en el contorno provincial. Los planes de centralización del país parecen derrumbarse también y los centralistas parecen refugiarse no ya en el Cabildo local sino en la Junta de Representantes.

Como se ve, durante el decenio revolucionario, el tan problemático Cabildo juega su papel del lado de estos últimos. De este modo, el poder político de la autoridad municipal y su dominio centralista, hacen de esta institución un elemento clave en la década revolucionaria. Sin embargo, en 1820, cuando pierden su control aparece la idea de reformarlo. Ciertamente, es posible suponer que una actitud oportunista dominó el clima reformista de ese año.

\section{A modo de conclusión}

1. Concluidos los enfrentamientos armados, ¿cómo piensan los centralistas al "otro" confederacionista? A grandes rasgos, no parece

68 Sobre este aspecto véase especial mente Ternavasio 2000. 
haber demasiadas diferencias entre las actitudes moderadas y conciliadoras adoptadas luego de octubre de 1820 y la asumida en los días posteriores a la tendencia confederacionista de 1816. Por un lado, se excluye a los segmentos más radicalizados, aquéllos que en los últimos momentos del conflicto deciden huir antes de rendirse, pero también se debe mencionar a los dos federales sentenciados a muerte por el tribunal militar. Carlos Heras señaló que esta última resolución no debería exagerarse, por cuanto las medidas ejemplificadoras no se extendieron a otros revolucionarios. No fue, por cierto, el destino que les tocó en suerte a los principales líderes federalistas. Todo parece indicar que se trató de dar una clara señal a la sociedad sobre lo que podría ocurrirle a los individuos que participaran en futuras tormentas políticas.

Por otro lado, se intentó unir a las fuerzas ganadoras y a las perdedoras. Para comprobar esta idea, fue necesario mostrar cómo en el corazón de la prensa periódica pero también en los mensajes emitidos por los hombres de poder político y militar de la provincia, se desplegó una amplia y machacona retórica de conciliación. Esa retórica fue acompañada además por medidas muy concretas que tendían a cumplir esas promesas: la reincorporación de militares en las nuevas unidades reformadas, el uso de uniforme y fueros para aquellos que quedan afuera de la reorganización de las fuerzas o el pasaporte que el gobernador le da a uno de los principales oficiales que participó en la revolución, Hilarión de la Q uintana.

2. Una sedición. Ésta es la noción que emplea el grupo vencedor para definir los sucesos revolucionarios de octubre. Esta visión de las cosas los lleva a marcar en la arena pública provincial varias cuestiones puntuales: los conflictos políticos violentos más recientes son el resultado del choque producido entre las distintas autoridades residentes en la ciudad en cuanto son poderes armados: por una parte el Cabildo sublevado y por otra, las fuerzas de la ley y del orden que rodean la figura legítima del gobernador propietario.

En ese marco de alteración y confusión, la emergencia de asambleas no permitidas por la ley fue una de sus salidas políticas más frecuentes, la cual deriva en un atentado contra el Estado, en una sedición. Las repuestas que se ofrecen son básicamente dos, una mayor subordinación de los poderes subalternos (como el Cabildo) bajo el ámbito del poder ejecutivo, y una suerte de política moral que ilustre 
a los ciudadanos sobre cómo deben actuar de acuerdo a las leyes vigentes. D esde este supuesto, se considera necesario que los porteños tomen conciencia de los atributos de cada autoridad.

La respuesta del grupo directorial de 1820 es bastante similar a la que ofrece el mismo sector luego de la tendencia confederacionista de 1816. Sin embargo, hay un aspecto novedoso. Es la idea de que -y no temamos insistir en esto- estas sediciones son el producto de un choque de autoridades y, en ese marco, se subraya que el Cabildo no tiene una dimensión política para intervenir en la escena. Como imaginará el lector, el argumento sirve no sólo para cuestionar a los sediciosos sino también para cortar en seco con la vida pública de esta institución. Poco tiempo después, se suprime ese reducto que refugiaba en los últimos tiempos a los grupos antidirectoriales. La descripción del itinerario del Cabildo nos permitió mostrar por un lado que efectivamente el Cabildo tuvo atribuciones políticas de primera importancia, en cuanto podía asumir la jefatura de la provincia en casos de crisis especialmente, pero por otro lado, la comprobación de que esa institución fue conducida por los sectores directoriales durante la década revolucionaria nos hizo comprender que se trató de un acto en verdad oportunista.

A partir de lo dicho hasta aquí, resulta por lo menos probable pensar que la reforma del estado de Buenos Aires realizada luego de 1820 no fue solamente para configurar un aparato estatal acorde a los nuevos tiempos de la expansión ganadera, un Estado que, como lo ha analizado Tulio Halperin Donghi en un verdadero trabajo clásico sobre el tema, proteja los intereses de la elite económica. Es del todo probable pensar que, además, al gunos de tales cambios tienen por objetivo también la construcción de un estado que elimine el problema de las intentonas revolucionarias: un poder ejecutivo más centralizado que logre tener más poder, es decir, no un estado que pueda ser dividido en varios poderes o autoridades que escondan detrás de sí futuras facciones, las cuales, una y otra vez, se enfrentan bélicamente con recursos humanos y materiales del estado.

\section{Referencias bibliográficas}

ARÁOZ DE LA M ADRID, G regorio (1947) Memorias, Tomo I, Buenos Aires, Biblioteca del suboficial. 
Fabián Herrero

ARCHIVO NACIO NAL, ARCHIVO DED ON BERNARD O O 'HIGG INS (1949), Tomo VI, Santiago de Chile, Imprenta U niversitaria.

BILBAO, Manuel (1919) Historia de Rosas, Buenos Aires, Ediciones Vaccaro.

BUSANICHE, José Luis (1984) Historia Argentina, Buenos Aires, Ediciones Solar.

CANSAN ELLO , Carlos (2003) De súbditos a ciudadanos. Ensayo sobre las libertades en los orígenes republicanos. Buenos Aires, 18101852, Buenos Aires, Imago M undi.

GARAVAGLIA, Juan Carlos (2003) "Ejército y milicia: los campesinos bonaerenses y el peso de las exigencias militares (1810-1860)", en: Anuario IEHS, no. 18, pp. 153-187.

GUERRA, Francois-Xavier (2000) Modernidad e independencias. Ensayos sobre las revoluciones hispánicas, México, FCE.

HALPERIN DONGHI, Tulio (1972) Revolución y Guerra. Formación de una élite dirigente en la argentina criolla, México, Siglo XXI.

HALPERIN DONGHI, Tulio (1982) Guerra y finanza en los orígenes del Estado Argentino (1791-1850), Buenos Aires, Editorial de Belgrano.

HERRERO, Fabián (1995) "Buenos Aires, año 1816. Una tendencia confederacionista", en: Boletín del Instituto de Historia Argentina y Americana "Dr. Emilio Ravignani", tercera serie, №.12.

HERRERO, Fabián (1999) "Indicios y estrategias. Lucha por el poder en Buenos Aires durante el critico año de 1820", Prohistoria, n. 3.

HERRERO, Fabián (2002) "Francisco de Paula Castañeda, (17761832). Sobre algunas líneas "bárbaras" en su discurso público", en Nancy Calvo, Roberto Di Stefano y Klaus Gallo, Los curas de la revolución. Vidas de eclesiásticos en los orígenes de la Nación, Buenos Aires, Emecé.

HERRERO, Fabián (2003)"Un golpe de estado en Buenos Aires durante octubre de 1820", en: Anuario IEH S, no. 18, pp. 67-85.

HERRERO, Fabián (2004) Revolución. Política e ideas en el Río de la Plata durante la década de 1810, Buenos Aires, Ediciones Cooperativas. 
HERRERO, Fabián (2007) "Escuchando la voz de los vencidos. Sobre la revolución federal de octubre de 1820, en: Revista Andes, no 18, pp. 13- 48.

RATTO, Silvia (2003) "Soldados, Milicianos e indios de "lanza y bola". La defensa de la frontera bonaerense a mediados de la década de $1830^{\prime \prime}$, en: Anuario IEHS, no 18, pp. 123-152.

ROSANVALLON, Pierre (1999) La consagración del ciudadano. $\mathrm{H}$ istoria del sufragio universal en Francia, México, Instituto Mora.

SÁENZ VALIENTE, José María (1952) Bajo la campana del Cabildo, Buenos Aires, Guillermo Kraft.

SALDIAS, Adolfo (1988) Buenos Aires en el centenario, volumen I, Buenos Aires, Hyspamérica.

SARTORI, Giovanni (1992) Partidos y sistemas de partidos, Buenos Aires, Alianza U niversidad.

SCHMIT, Roberto (2004) Ruina y resurrección en tiempos de guerra. Sociedad, economía y poder en el oriente entrerriano posrevolucionario, 1810-1852, Buenos Aires, Prometeo.

TERNAVASIO, Marcela (2000) "La supresión del Cabildo de Buenos Aires: ¿Crónica de una muerte anunciada?", en: Boletín del Instituto de Historia Argentina y Americana "Dr. Emilio Ravignani", tercera serie, no 21, 1er. Semestre, pp. 33-73.

\section{Resumen}

Este trabajo se ocupa de algunas creencias y actitudes producidas por los grupos vencedores del gol pe de estado de octubre de 1820. Se intenta demostrar que los sectores centralistas desplegaron luego de esos violentos episodios políticos, una línea retórica de conciliación que puede detectarse en las publicaciones periódicas y en los mensajes emitidos por los hombres de poder político y militar de la provincia. Dicha retórica fue acompañada de medidas adoptadas desde las esferas del poder ejecutivo provincial y que tenían como finalidad la integración de algunos sectores federales recientemente derrotados. Esta comprobación permite matizar la idea de que los vencedores de octubre iniciaron una intensa venganza sobre los grupos derrotados, la cual podía advertirse en las nuevas reformas militares en donde no figuraría ningún ex revolucionario. 
Fabián Herrero

Palabras clave: Golpe de estado, federalismo, centralismo, política, Buenos Aires.

\section{Law and order. Buenos Aires by the late 1920's \\ Summary}

This paper deals with some beliefs and attitudes produced by the victorious groups of the coup d'état that took place in O ctober 1820. W e attempt to show that after these violent political episodes, centralist sectors displayed a conciliatory rhetoric that can be traced in periodicals and in the messages announced by men with political and military power in the province. Such a rhetoric was accompanied by measures taken by the provincial executive power and they were intended to integrate some federal sectors recently defeated. This statement allows to question the idea that 0 ctober winners started an intense revenge over defeated groups, which could be noticed in the new military reforms where no former revolutionary would be included.

Key Words: coup d'état, federalism, centralism, politics, Buenos Aires.

Recibido: 15/08/06; aceptado: 03/06/07. 